\title{
Anticancer Efficacy of Some Plant Phenolics - A Recent Scenario
}

\author{
Mukesh Chander* \\ Department of Biotechnology, Khalsa College (Autonomous), Amritsar - 143002, \\ Punjab, India \\ *Corresponding author
}

\begin{abstract}
A B S T R A C T
The bioactive compounds are extra nutritional constituent that typically occur in small quantities in seeds, bark, fruit, foods and other plant parts. They are being intensively studied to evaluate their effects on health. The results of many epidemiologic studies have shown protective effects of plant-based diets/phenolics on cancer. Many bioactive

Keywords

Plant phenolics,

Flavonoids, Phenolic

acids, Tannins, Bioactive

compounds, Cancer

\section{Article Info}

Accepted:

12 September 2018

Available Online:

10 October 2018 compounds have been discovered. These compounds vary widely in chemical structure and function and are grouped accordingly. Phenolic compounds, including their subcategory, flavonoids and phenolic acids are present in all plants and have been studied extensively in cereals, legumes, nuts, olive oil, vegetables, fruits, tea, and red wine. Many phenolic compounds have antioxidant properties, and some studies have demonstrated favorable effects on thrombosis and tumorogenesis and promotion. Cancer is the loss of controlled growth regulation. Tumorogenesis can be activated by environmental carcinogens, inflammatory agents, and tumour promoters which modulate transcription factors, anti-apoptotic proteins, pro-apoptotic proteins, protein kinases, cell cycle proteins, cell adhesion molecules, and growth signalling pathways. Although some epidemiologic studies have reported protective associations between flavonoids or other phenolics and CVD and cancer, other studies have not found these associations. Hydroxytyrosol, one of many phenolics in olives and olive oil, is a potent antioxidant. Resveratrol, found in nuts and red wine, has antioxidant, antithrombotic, and anti-inflammatory properties, and inhibits carcinogenesis.
\end{abstract}

\section{Introduction}

Phenols are a class of organic compounds, having aromatic hydrocarbon groups and attached $-\mathrm{OH}$ group. They are also called as phenolics. They are widely distributed in plant kingdom. These compounds are the most abundant secondary metabolites (Dai and Mumper, 2010). In recent years of research it came into notice that, these compounds have an important role in cancer prevention and treatment of various stress related diseases. Phenolic compounds include phenolic acids, flavonoids, tannins, stibenes, curcuminoids, coumaris, lignans, quinines and many others (Khoddami et al., 2013). The most commonly used method to extract plant phenolics is organic solvent extraction. These compounds are extracted and then purified from various medicinal plants, fruits and vegetables. These compounds contribute in various cellular activities like apoptosis by arresting the cell 
cycle, cell adhesion, migration, proliferation or differentiation (Amin et al., 2009).

These compounds (phenolic acids, flavonoids, tannins etc.) come under category of reactive oxygen species (ROS). Normal cells have low level of ROS if, it is increased in cancer cells the defense system get activated against ROS. These species prevent the transformation of normal cell to cancer cells. The categories berries and berry products, fruits and fruit juice, nuts and seeds, breakfast and cereals, chocolates and sweets, common food and beverages etc. have low to high antioxidant values.

The $75 \%$ of anti-oxidative content threshold for plant based food is $4.11 \mathrm{mmol} / 100 \mathrm{~g}$. sangre de grado (dragon's blood) a plant found in Peru has highest antioxidative content of all plant species $(2897.1 \mathrm{mmol} / 100 \mathrm{~g})$. In india plants like triphala, amalaki, arjuna has antioxidative value ranges from $132.6 \mathrm{mmol} / 100 \mathrm{~g}$ to $706.3 \mathrm{mmol} / 100 \mathrm{~g}$ (Paur et al., 2011). There are more than 8000 phenolic structures are known, found in various plants, fruits, vegetables, cereals, olive etc. Phenolics are responsible for colour of some fruits and vegetables mostly of red, purple colour. They also act as flavor enhancing agents in red wine and other fruit juices (Cheynier, 2012).

Almost all phenolic compounds have following biological and chemical properties of antioxident activities, ability to scavenge antioxygen species, to scavenge electrophiles, to inhibit nitrosation, to chelate metals and the potential for anti-oxidation, producing hydrogen peroxide in the presence of certain metals. The phenolics can be naturally occurring and are also synthesized from naturally occurring flavonoids are the most abundant. Synthetic compounds are manufactured in laboratories by using phenols as parent constituents. Various synthetic compounds are Bisphenol A, Butylated hydroxytoluene (BHT), orthophenylphenol, picric acid, phenol phthalein, xylenol, 4nonphenylphenol etc (Huang and Thomas, 1992; Huang et al., 2010).

Chemotherapy is an effective way to cure various cancerous cell lines, but the cost is very high that common man cannot afford to take such a costly treatment. Moreover the drugs used most of them cause several side effects, specially to normal cells. Therefore development of new anticancer phenolic compounds is important (Senawong et al., 2014).

\section{Types of phenolic compounds}

The polyphenols are catagorised according to the number of phenol rings and its structure, into three main sub groups: flavonoids, nonflavonoids polyphenols and tannins (Figure 1).

Another group namely tannins are polyphenolic compounds. These tannins are the condensed form of gallic acid. They are found in very high concentration in grape seed (Ananga et al., 2013). Apart from grapes, tannins are widely distributed into plant flora. They have high molecular weight and are soluble in water and alcohol. They basically found in root, bark, stem and outer layer of plant tissue. They form complexes with proteins, carbohydrates, gelatin and alkaloids and has very high antioxidant and antibacterial activity (Widsten et al., 2014).

\section{Flavonoids}

These are polyphenolic compounds found most abundantly in vegetables, fruits and many other daily dietary food components. They are potential bioactive compounds having variable potential like anti-mutagenic, anti-allergic, anti-inflammatory, antioxidant and anti-carcinogenic effects. These compounds also have capability to modulate 
activities of various enzymes. They are water soluble and accumulate in cell vacuoles. There are six flavonoid subgroup namely flavonols, flavones, isoflavones, flavanols, flavanones and flavanonols (Ren et al., 2003).

\section{Classification of flavonoids}

Flavonoids are the most abundant, about 4000 flavonoids are known among all phenolics. They are heat stable and are consumed by an individual a few hundred grams per day. They can be classified on the basis of degree of unsaturation and oxidation of $\mathrm{C}$ ring. Flavonoids in which $\mathrm{B}$ ring is linked with 3 of ring $\mathrm{C}$ are called isoflavonoids, and when linked with 4, it is called neoflavonoids. Apart from isoflavonoids and neoflavonoids there are six sub groups of flavonoids as shown in Table 1. They are the major phenolis found in onion, apple, broccoli etc. The basic structure is flavon, having 15 carbons arranged in three ring structures (Figure 2).

\section{Uses}

These compounds have a vast area of applications not only in medical or research area, flavonoids have a significant importance in food industries and lather industries etc. In food flavonoids are flavor enhancers they are widely used in alcohol fermentation industries they are good sweetening agent moreover the taste of common beverages such as wine beer or tea is also caused by flavonoids (Brodowska, 2017). In addition to antioxidant properties, flavonoids exhibit some biological effects for e.g., antiviral, antibacterial, antiinflammatory, vasodilatory, anti-ischemic and anticancer (Alvesalo et al., 2006).

\section{General chemical structure of flavonoids}

Flavonoids are composed of commonly phenylbenzopyrone or diphenylpropane structure, two benzene rings linked by a three carbon chain that form a closed pyran ring (ring containing oxygen) with benzoic A ring. Therefore, the structure is represented as C6C3-C6 categorized on the basis of saturation level and opening of central pyran ring. B ring attached to position 2 of $\mathrm{C}$ ring but it can also bind to 3 or 4 (Figure 3 ). The hydroxylation and glycosylation of rings make flavonoids a diversified group of phyto chemicals (Huang and Thomas, 1992; Huang et al., 2010).

\section{Structure of subgroups}

\section{Flavones}

Flavones have double bond is between 2 and 3 of $\mathrm{C}$ ring. Hydroxyl group at position 5 of ring A. A ketone at 4 of ring C. Glycosylation occur on position 5 and 7 , methylation and acylation on the hydroxyl group of the B ring (Figure 4). Example: nobiletin and tangeretin are polymethoxylated (Han et al., 2007). They are also called yellow solids. Flavones are soluble in water, ethanol and some dilute acids. They are precipitated by lead salts. On their reaction with ferric chloride, flavones give dull green and red brown colour (Pandey and SI, 2009).

Flavones are of two type natural and synthetic, natural flavones include apigenin (4',5,7trihydroxyflavone), luteolin ( $3^{\prime}, 4^{\prime}, 5,7-$ tetrahydroxyflavone), 6-hydroxyflavone, 7,8dihydroxyflavone, baicalein $\quad(5,6,7$ trihydroxyflavone), scutellarein (5,6,7,4'tetrahydroxyflavone), and wogonin (5,7dihydroxyflavone) and synthetic flavones are diosmin and flavoxate (flavones, taken from wikipedia).

\section{Flavonols}

Flavonols have hydroxyl group at position 3 of the $\mathrm{C}$ ring it can also be glycosylated. They are the most common and large subgroup among all flavonoids in fruit and vegetables. 
They are diverse in hydroxylation and methylation patterns (Figure 5). Example: Quercetin is present in many plant foods.

Flavonols exhibit cellular activities, antiinflammatory and anticarcinogenic properties. They also suppress Topoisomerase I-mediated relaxation reaction. Quercetin being planar aromatic flavonol binds to DNA because of presence of double bond between 2 and 3 carbon of $\mathrm{C}$ ring (Esselen et al., 2014).

\section{Flavanones}

Flavanones are also called dihydroflavones, and saturated $\mathrm{C}$ ring. The flavanones can be multi-hydroxylated and several hydroxyl groups can be glycosylated or methylated (Figure 6). Example: furanoflavanones, prenylated flavanones, pyranoflavanones and benzylated flavanones.

Flavonones supports and enhance the body defense against oxidative stress and prevent cardiovascular diseases, atherosclerosis, and cancer (Davide et al., 2017).

\section{Flavanols}

Flavanols are 3-hydroxy derivatives of flavanones. They are highly diversified and multi substituted subgroup. They are also called flavanols or flavan-3-ol (Figure 7).

\section{Isoflavones}

Isoflavones have structural similarities to estrogen such as estradiol because of it they are also called phyto estrogen. The $\mathrm{B}$ ring attached to position 3 of ring $\mathrm{C}$ (Figure 8).

\section{Anthrocynidins}

Anthrocynidins are flavylium cation and are present in form of chloride salts. This group of flavonoids has importance in various research programs as they are the only flavonoids those give plant colors (all other flavonoids are colorless). Sugar units are bound to position 3 of $\mathrm{C}$ ring (Figure 9). The color depends upon the $\mathrm{pH}$ and methylation at hydroxyl group on $\mathrm{A}$ and $\mathrm{B}$ rings (Tsao, 2010).

\section{Phenolic acid}

Phenolic compounds exist in most plant tissues as secondary molecules there are total 30 phenolic acids are found. Phenolic acids and flavonoids are considered as important components because of the beneficial effects on human health. They are constantly distributed in foods, fruit juices and beverages from plants. Phenolic acids show various bioactive and therapeutic properties, such as antioxidant, anticancer, antiviral and cardiac protective effects (Nile and Park, 2014).

The phenolic acid are important to human diet due to their potential antioxidant activities, like their ability to reduce oxidative stress induced due to certain chronic diseases, and their potential important activities such as anticancer activities (Figure 10). The bioactive substance investigation (A bioactive substance is that, which is biologically active and play important role in certain biological processes.) of Balanophora involucrata obtained 15 phenolic acids, including 5 new compounds (Wei et al., 2017).

Phenolic acids are consists of an aromatic ring carrying one or more hydroxyl phenol moieties. On the basis of their structure the phenolic compounds are further grouped as following:

Simple phenol

Benzoic acid

Hydrolysable tannins

Acetophenones

Phenylacetic acid

Cinnamic acid 
Lignans

Coumarins

Benzophenones

Xanthones

Stilbenes

Secoiridoids

Phenolic acid is aboundent in fruits, vegetables and other dietary components. The common phenol acids are ferulic acid found in cereals (Ananga et al., 2013).

\section{Tannins}

These compounds are the second major group of phenolics, divided into two major components. The features distinguishing tannins from other types of plant-based polyphenols are basically the properties of the binding of tannins to proteins, basic compounds, pigments, large-molecular compounds and metallic ions and also the display of anti-oxidant activities. Tannins have a characteristic feature to tannic to convert things into the color of leather (Figure 11 and 12). They are acidic in reaction and this is attributed to the presence of phenolic or carboxylic groups (Kar and Ashutosh, 2007).

Hydrolysable tannins contain central core of glucose example: gallotannins. Condensed tannins contain oligomers or polymers of flavon-3-ol linked through an interflavon carbon bonds (Gonzalez et al., 2012).

The gallotannins and the tannins biogenetically derivable from gallotannins can be classified into four types: I (gallotannin), II (ellagitannin), III (dehydroellagitannin) and IV (oxydatively transformed dehydroellagitannin) (Figure 11).

\section{Methods of extraction}

Phenolic compounds are extracted from various plants, vegetables, flowers, leaves and fruits etc. the first step is, to select a plant or plants from which sample extraction is to be performed. The sample material can be flowers, leaves and fruit etc.

\section{Preparation of extraction sample (Hayouni et al., 2007)}

Sample material was collected from various sources, then dried and powdered (let 50g), which was further dissolved in distilled water and $1 \mathrm{~L}$ ethanol.

The solution was then heated at $65^{\circ} \mathrm{C}$ for 2 hours.

The heated solution cooled and filtered through whatman filter paper followed by evaporation to remove excess of solvent.

The residues were freeze dried and kept at $20^{\circ} \mathrm{C}$ for future analysis.

Extraction of total phenolic acid content (Jayaprakasha and Patil, 2007)

$200 \mu \mathrm{L}$ of plant extract was diluted by dissolving it in $20 \mathrm{ml}$ distilled water and added Folin-ciocalteu reagent (10 fold diluted; $1 \mathrm{ml}$ ).

The dilution prepared in total darkness for $10 \mathrm{~min}$ was incubated at room temperature.

Sodium carbonate $(7.5 \%, 1 \mathrm{ml})$ was added to aliquot and incubated for $30 \mathrm{~min}$.

Absorbance was read at $765 \mathrm{~nm}$. Different concentrations of gallic acid were used to prepare a calibration curve.

\section{Extraction of total flavonoid content (Ghasemzadeh and Hawa, 2013; Ghasemzadeh et al., 2015)}

The extract was taken and mixed with $\mathrm{NaNO}_{2}$ (sodium nitrate) in methanolic solution and 
incubated at room temperature for $6 \mathrm{~min}$. Added $0.3 \mathrm{ml}$ of $\mathrm{AlCl}_{3}$ solution and mixed nicely, then the solution rested for $6 \mathrm{~min}$ (without disturbing).

$1 \mathrm{M} \mathrm{NaOH}(2 \mathrm{ml})$ was added in each extraction dilution prepared for total flavonoid content.

Incubated for $10 \mathrm{~min}$ at room temperature and the absorbance was read at $510 \mathrm{~nm}$ using spectrophotometer.

\section{Extraction of total tannin content}

$0.5 \mathrm{ml}$ of extract was diluted with methanol to made the volume up to $5 \mathrm{ml}$.

Vanillin reagent was prepared (by dissolving $1 \mathrm{~g}$ vanillin in $100 \mathrm{ml}$ methanol) and filtered to obtain clear solution.

Extract was dissolved in $25 \mathrm{ml}$ of vanillin reagent and then $25 \mathrm{ml}$ of $4 \% \mathrm{HCL}$ in methanol. The mixture was than kept in dark for $15 \mathrm{~min}$ at room temperature.

The absorbance was taken at 500nm in triplicates while methanol was used as blank.

The authors have used the strategies for preparation and characterization of phenolic samples from plant materials prepared by above listed methods using various biochemical techniques. However Dai and Mumper (2002), have used combination of different biochemical techniques to obtain pure bioactive phenolics from crude plant extracts (Figure 13).

Where MAE: Microwave-assisted extraction; UAE: Ultrasound-assisted extraction; PFE: Pressurized fluid extraction; PLE: Pressurized liquid extraction; ASE: Accelerated solvent extraction; SWE: Subcritical water extraction; SFE: Supercritical fluid extraction; SPE: Solid phase extraction; CCC: Countercurrent chromatography; FD: Folin-Denis method; F-
C: Folin-Ciocalteu method; GC: Gas chromatography; LC: Liquid chromatography; FLU: Fluorescence

PDA: Photodiode array; EAD: Electro-array detection; ECD: Electrochemical detection; MS: Mass spectrometric; NMR: Nuclear magnetic resonance.

\section{Flavonoids and their role in combating cancer}

\section{Epidermiological data}

Flavanones are considered inversely related to esophageal cancer. The reduced risk of cancer is observed with intake of high amount of anthocyanidins, flavonols, flavones, and isoflavones. Isoflavones are inversely associated to ovarian cancer whereas flavones were associated to renal cancer (Rossi et al., 2010). A protective effect of flavonoids is associated with vitamin C, studied on esophageal cancer (Rossi et al., 2007).

Anti-cancer activities of methanolic flower extract of Tecoma stans (METS) was evaluated by both in vitro (Vero and Hep 2 cell lines) and in vivo (using ehrlich ascites carcinoma tumor model) method, these method results are than compared with 5flurouracil. As a result a significant dosedependent activity was indicated (Kameshwaran et al., 2012) Flavonoids display a vast array of cellular effects. The effect overall process of Carcinogenesis by several mechanism including inhibition of DNA Topoisomerase $1 \backslash 2$ activity, decreased or increased in relative oxygen species, DNA oxidation and fragmentation, regulation of heat-shock-protein expressions, etc.

\section{Biomolecular activities}

Antioxidative effects inactivation of oxygen radicals 
Fig.1 Basic structure of flavonoids and non-flavonoids<smiles>c1ccc(C2CCc3ccccc3O2)cc1</smiles><smiles>O=C(O)c1ccccc1O</smiles><smiles>O=C(O)/C=C/C1=COC=CC=[R]1</smiles>

Flavonoids

Hydroxybenzoic acids Hydroxycinnamic acids

Phenolic acids (from non-flavonoids group)

Fig.2 Biosynthesis of flavonoids (Adapted from Batra et al., 2013)

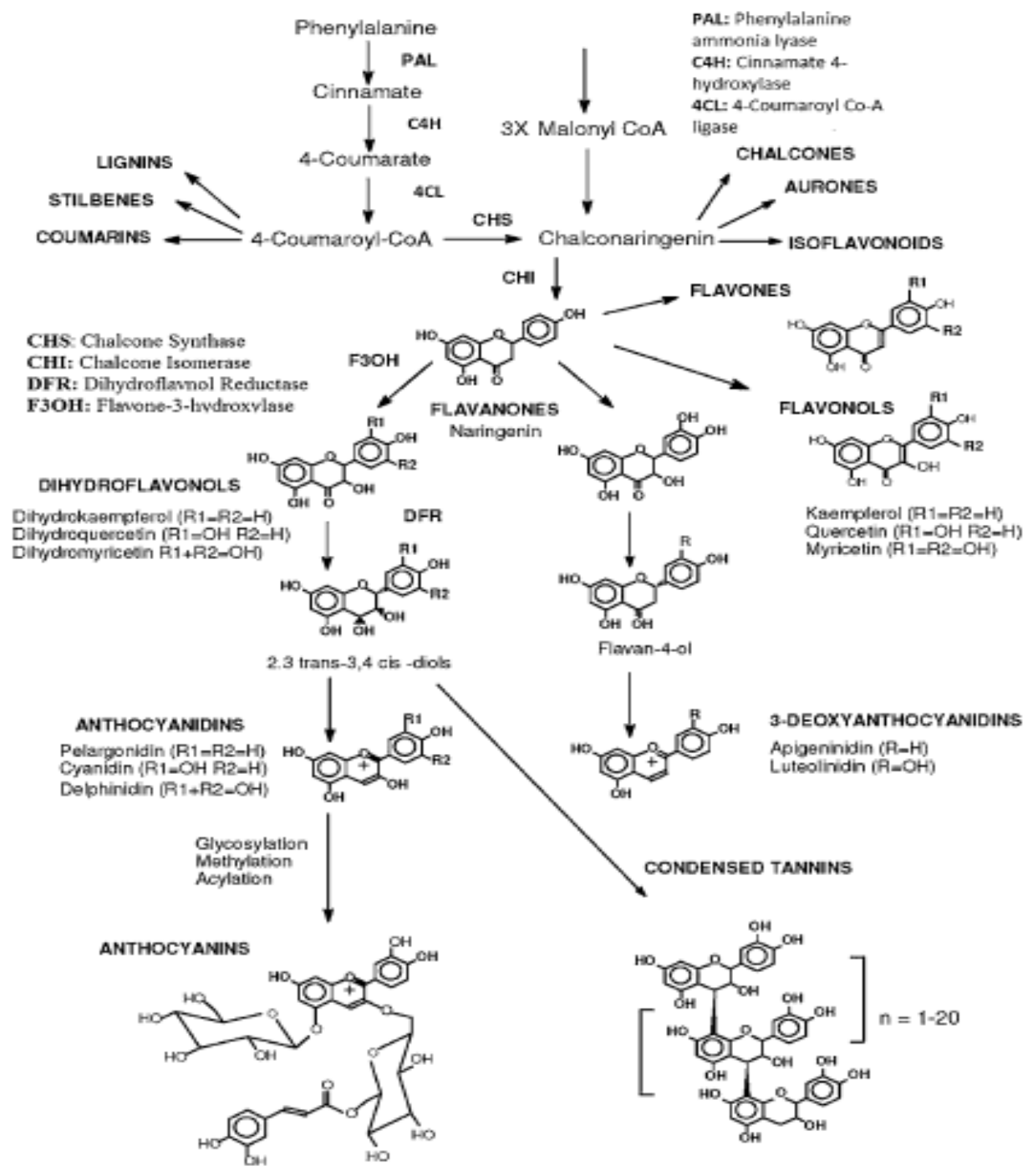


Fig.3 Structure of diphenylpropane (Adapted from Jia et al., 2013)

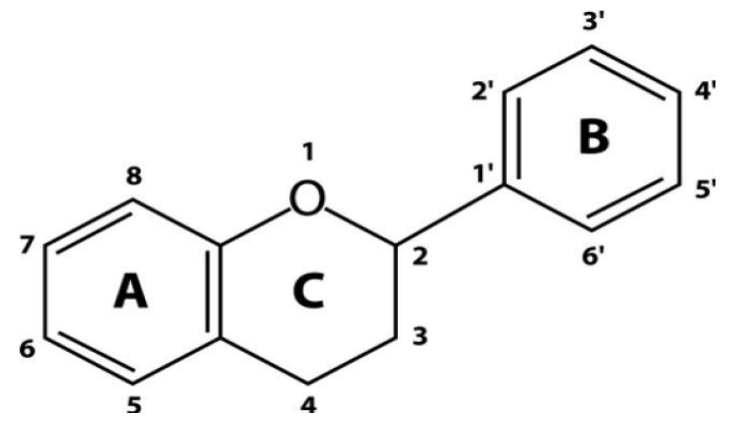

Fig.4 Structure of flavones

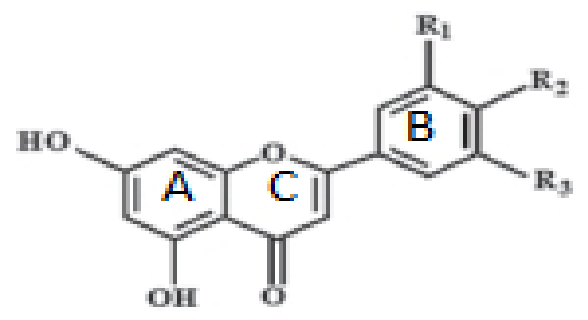

Flavones

Fig.5 Structure of flavonols

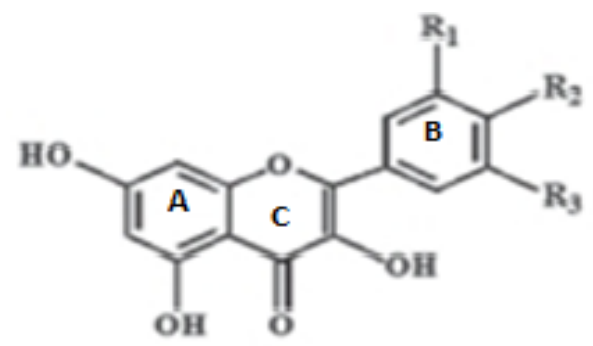

\section{Flavonols}

Fig.6 Structure of flavanones

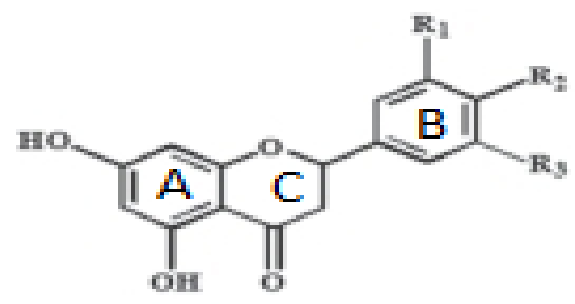

Flavanones 
Fig.7 Structure of flavanols

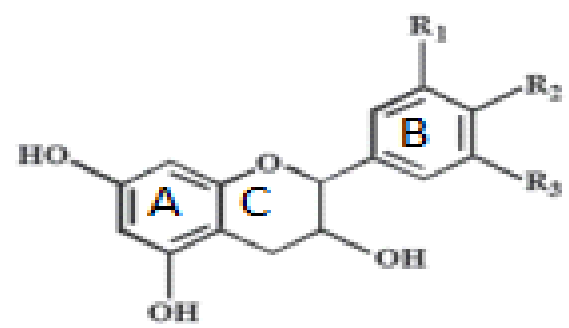

Flavanols

Fig.8 Structure of isoflavones

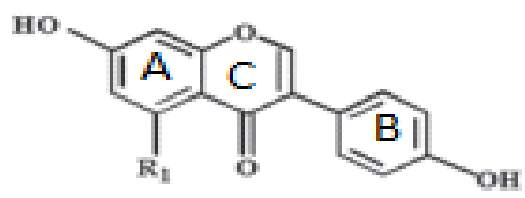

Isoflavones

Fig.9 Structure of anthrocyanins

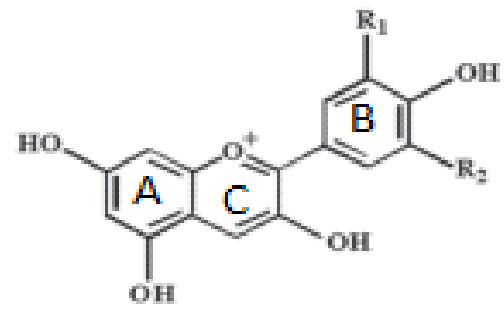

Anthocyanins

Fig.10 Basic structure of two main groups of phenolic acids found in plants

\section{Hydroxybenzoic acid}

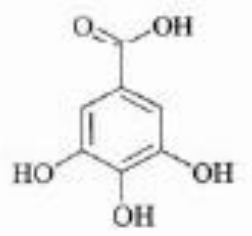

Gallic acid

\section{Hydroxycinnamic Acid}

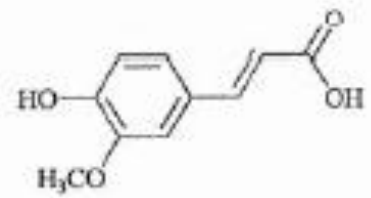

Ferulic acid

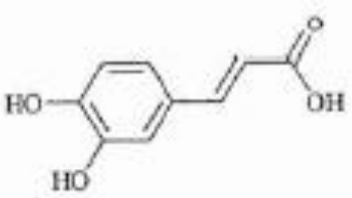

Caffeic acid 
Fig.11 Structure of Hydrolysable tannins and their product

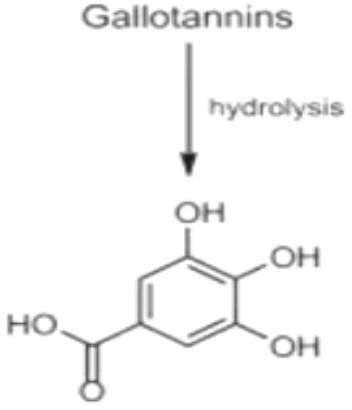

Gallic acid<smiles>O=c1oc2c(O)c(O)cc3c(=O)oc4c(O)c(O)cc1c4c23</smiles>

Ellagic acid

Fig.12 Structure of tannin (Adapted from Vuong et al., 2014)<smiles></smiles>

Fig.13 Strategies for preparation and characterization of phenolic samples from plant materials. (Adapted from Dai and Mumper, 2002)

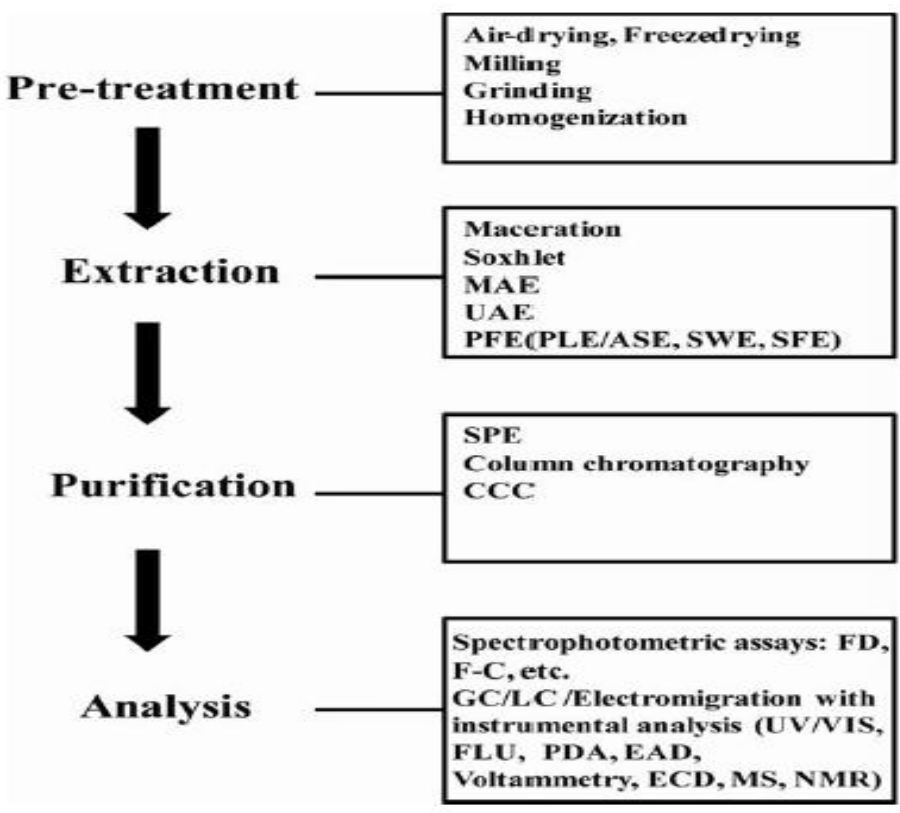


Fig.14 Different stages of cancer development and progression (Adapted from Chahar et al., 2011)

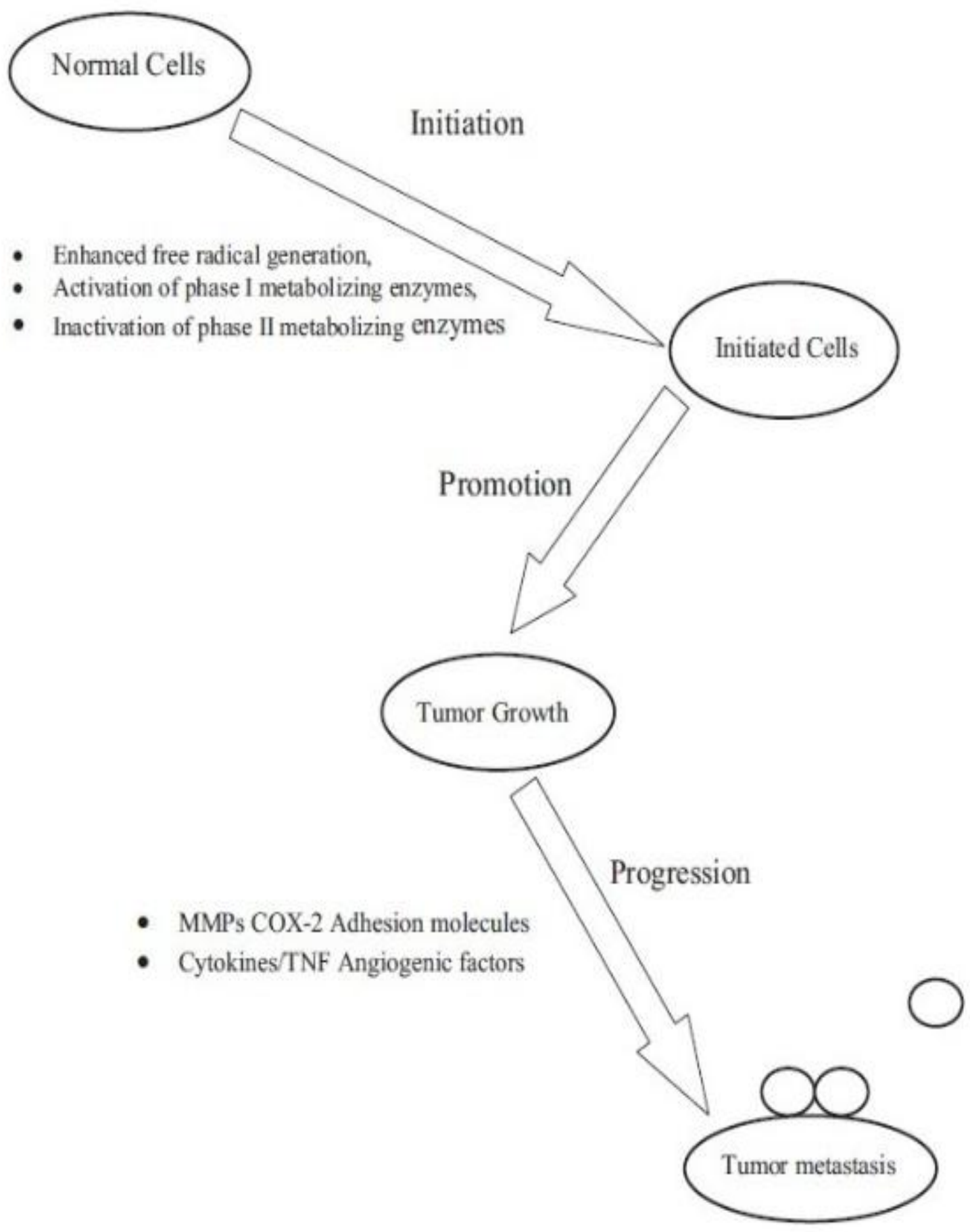


Fig.15 Overall effect of polyphenolic acids on cancer progression (Adapted from Manson, 2003)

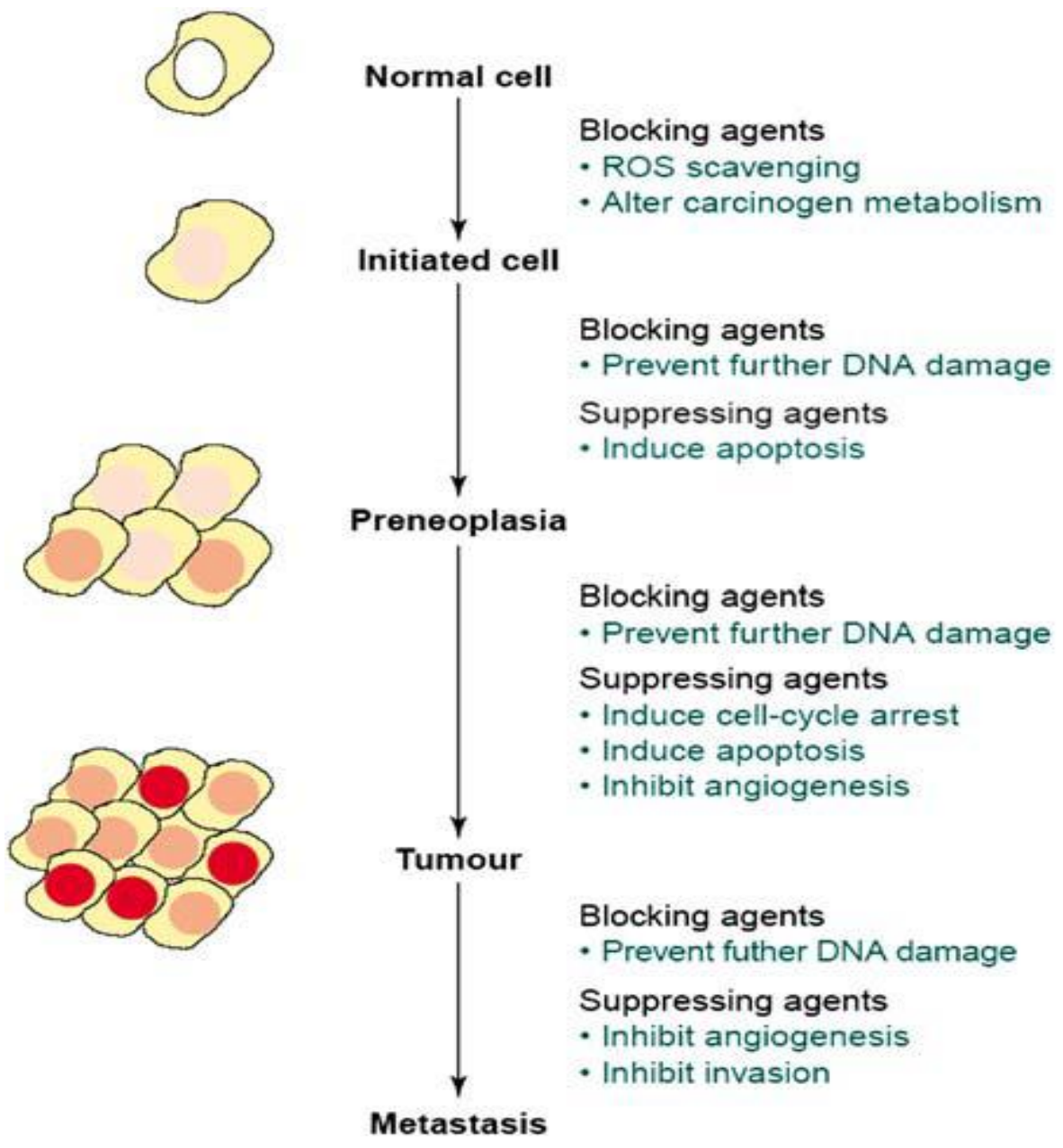

Fig.16 Anticancer mechanism of phenolic acid

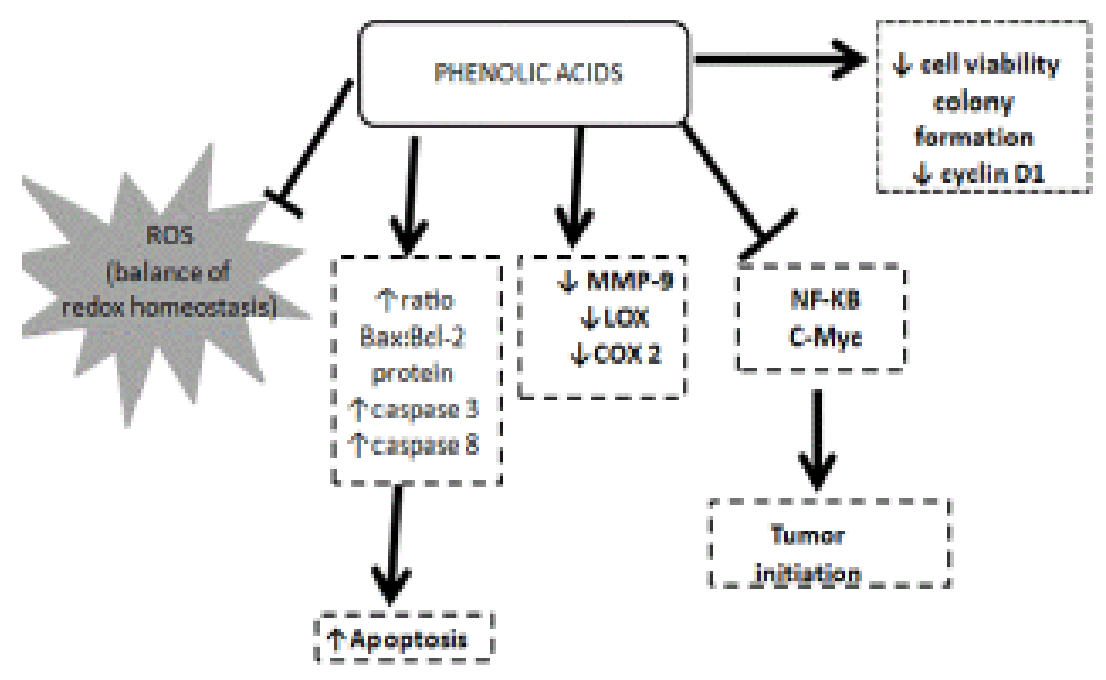


Fig.17 Different types of Gallotannins (Adapted from Okuda and Ito, 2011)

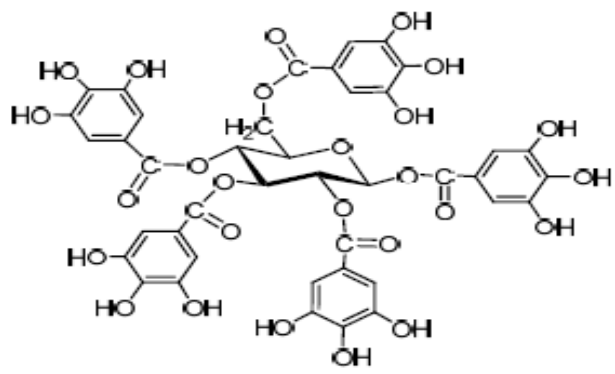

Penta-O-galloyl- $\beta-D-$ glucose

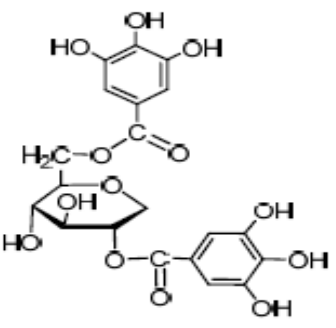

Acertannin

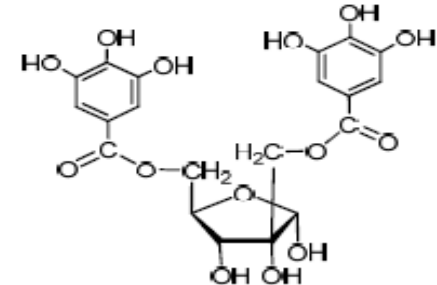

Hamamelitannin

Fig.18 Mechanism of action by bioactive compound (steviol, a flavonoid)

(Adapted from: Gupta et al., 2017)

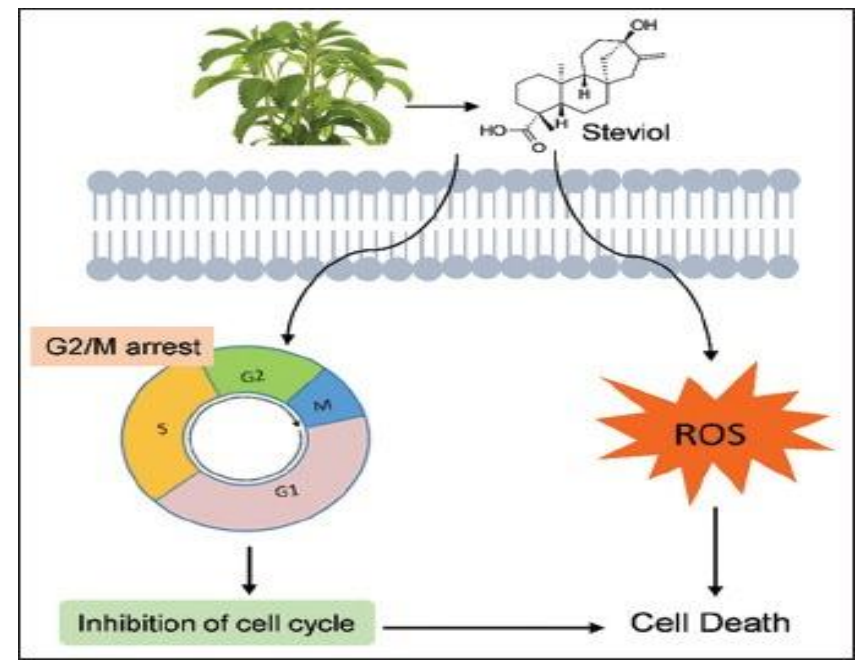

Table.1 Main groups of flavanoids and their representative components (Ren et al., 2003)

\begin{tabular}{|c|c|c|c|}
\hline S.no & Flavonoid & Representative flavonoids & Major food sources \\
\hline 1 & Flavonols & $\begin{array}{l}\text { Kaempherol, myricetin, quercetin, } \\
\text { rutin }\end{array}$ & $\begin{array}{l}\text { Onions, apple, cherries, kale, tomato, } \\
\text { tea, red wine, berries, broccoli }\end{array}$ \\
\hline 2 & Flavones & Apigenin, chrysin, luteolin & Parsley, thyme \\
\hline 3 & Isoflavones & $\begin{array}{l}\text { Daidzein, genistein, glycitein, } \\
\text { formononetin }\end{array}$ & Soya beans, legumes \\
\hline 4 & Flavanols & Catechin, gallocatechin & Apple, tea \\
\hline 5 & Flavanones & Eriodictyol,hesperitin, naringenin & Orange, grape fruit \\
\hline 6 & Flavanonols & Taxifolin & Limon, aurantium \\
\hline
\end{tabular}


Table.2 Hydroxybenzoic acid and hydroxylcinnamic acid

\begin{tabular}{|c|c|c|c|c|c|}
\hline Hydroxybenzoic acid & Name & R1 & $\mathbf{R 2}$ & $\mathbf{R 3}$ & R4 \\
\hline & Benzoic acid & $\mathrm{H}$ & $\mathrm{H}$ & $\mathrm{H}$ & $\mathrm{H}$ \\
\hline & p-Hydroxybenzoic acid & $\mathrm{H}$ & $\mathrm{H}$ & $\mathrm{OH}$ & $\mathrm{H}$ \\
\hline $\mathrm{OH}$ & Vanillic acid & $\mathrm{H}$ & $\mathrm{OCH}_{3}$ & $\mathrm{OH}$ & $\mathrm{H}$ \\
\hline & Gallic acid & $\mathrm{H}$ & $\mathrm{OH}$ & $\mathrm{OH}$ & $\mathrm{OH}$ \\
\hline & Protocatectechuic acid & $\mathrm{H}$ & $\mathrm{OH}$ & $\mathrm{OH}$ & $\mathrm{H}$ \\
\hline & Syringic acid & $\mathrm{H}$ & $\mathrm{OCH}_{3}$ & $\mathrm{OH}$ & $\mathrm{OCH}_{3}$ \\
\hline & Gentisic acid & $\mathrm{OH}$ & $\mathrm{H}$ & $\mathrm{H}$ & $\mathrm{OH}$ \\
\hline $\mathrm{R}_{2}$ & $\begin{array}{l}\text { Veratric acid } \\
\text { Salicylic acid }\end{array}$ & $\begin{array}{c}\mathrm{H} \\
\mathrm{OH}\end{array}$ & $\begin{array}{c}\mathrm{OCH}_{3} \\
\mathrm{H}\end{array}$ & $\mathrm{OCH}_{3}$ & $\mathrm{H}$ \\
\hline Hydroxycinnamic acid & Name & R1 & $\mathbf{R} 2$ & $\mathbf{R 3}$ & R4 \\
\hline $\mathrm{cc}$ & Cinnamic acid & $\mathrm{H}$ & $\mathrm{H}$ & $\mathrm{H}$ & $\mathrm{H}$ \\
\hline & o-Coumaric acid & $\mathrm{OH}$ & $\mathrm{H}$ & $\mathrm{H}$ & $\mathrm{H}$ \\
\hline & m-Coumaric acid & $\mathrm{H}$ & $\mathrm{OH}$ & $\mathrm{H}$ & $\mathrm{H}$ \\
\hline & p-Coumaric acid & $\mathrm{H}$ & $\mathrm{H}$ & $\mathrm{OH}$ & $\mathrm{H}$ \\
\hline & Ferulic acid & $\mathrm{H}$ & $\mathrm{OCH}_{3}$ & $\mathrm{OH}$ & $\mathrm{H}$ \\
\hline & Sinapic acid & $\mathrm{H}$ & $\mathrm{OCH}_{3}$ & $\mathrm{OH}$ & $\mathrm{OCH}_{3}$ \\
\hline $\mathrm{R}_{2}$ & Caffeic acid & $\mathrm{H}$ & $\mathrm{OH}$ & $\mathrm{OH}$ & $\mathrm{H}$ \\
\hline
\end{tabular}

(Adapted from Goleniowski et al., 2013)

Table.3 Epidermiological studies of flavonoids (Adapted from Gil et al., 2005)

\begin{tabular}{|c|c|c|}
\hline Sources & Effect & Sample \\
\hline Flavonoids & $\begin{array}{l}\text { Decreased cancer risk in all sites combined } \\
\text { Decreased cancer risk in oral cavity, pharynx, larynx and esophagus } \\
\text { Nonreduced risk of bladder cancer } \\
\text { Nonreduced risk of cancer incidence } \\
\text { Nonreduced risk of lung cancer }\end{array}$ & $\begin{array}{l}9959 \text { Men } \\
540 \text { People } \\
497 \text { People } \\
728 \text { Men } \\
103 \text { Women }\end{array}$ \\
\hline $\begin{array}{l}\text { Quercetin, } \\
\text { onions, white } \\
\text { grapes }\end{array}$ & Decreased recurrence of lung cancer & 582 People \\
\hline Quercetin & & \\
\hline Myricetin & Decreased incidence of lung cancer & 10,054 Men \\
\hline $\begin{array}{l}\text { Quercetin, } \\
\text { Kaempferol }\end{array}$ & $\begin{array}{l}\text { Decreased risk of prostate cancer } \\
\text { Decreased risk of gastric cancer }\end{array}$ & 354 People \\
\hline Catechins & Decreased incidence of rectal cancer & $\begin{array}{l}\text { 34651 Women } \\
\text { 12,170 People }\end{array}$ \\
\hline $\begin{array}{l}\text { Tea } \\
\text { Green tea }\end{array}$ & $\begin{array}{l}\text { Decreased risk of colon cancer } \\
\text { Reduced risk of cancer in different organs } \\
\text { Decreased risk of breast cancer recurrence and metastasis }\end{array}$ & $\begin{array}{l}8552 \text { People } 472 \\
\text { People }\end{array}$ \\
\hline Black tea & $\begin{array}{l}\text { No association with gastric cancer } \\
\text { No association with risk of colorectal, stomach, lung and breast cancers } \\
\text { Decreased risk of lung cancer }\end{array}$ & $\begin{array}{l}11,902 \text { Men and } \\
14,409 \text { women } \\
58,279 \text { Men and } \\
62,573 \text { women }\end{array}$ \\
\hline Soya & Decreased risk of breast cancer & $\begin{array}{l}999 \text { Men } 34,759 \\
\text { Women }\end{array}$ \\
\hline
\end{tabular}


Table.4 Anticancer activities of flavonoids in various cancer cell lines

\begin{tabular}{|l|l|l|}
\hline $\begin{array}{l}\text { Cancer } \\
\text { Human oral } \\
\text { cancer }\end{array}$ & HSC-2,HSG,SCC-25 & $\begin{array}{l}\text { Flavonoid } \\
\text { Flavanones,isoflavones,EGC,chalcones,EGCgenist } \\
\text { ein,ECG, quercetin, cisplatin }\end{array}$ \\
\hline $\begin{array}{l}\text { Human breast } \\
\text { cancer }\end{array}$ & MCF-7 & Flaanones,daidzein,genistein,quercetin,luteolin \\
\hline $\begin{array}{l}\text { Human } \\
\text { thyroid cancer }\end{array}$ & ARO,NPA,WRO & Genistein,apigenin,kaempferol,chrysin,luteolir \\
\hline $\begin{array}{l}\text { Human lung } \\
\text { cancer }\end{array}$ & $\begin{array}{l}\text { SK- } \\
\text { LU1,SW900,H441,H66 } \\
\text { 1,haGo-K-1,A549 }\end{array}$ & Flavones,quercetin \\
\hline $\begin{array}{l}\text { Human } \\
\text { prostate } \\
\text { cancer }\end{array}$ & LNCaP,PC3,DU145 & $\begin{array}{l}\text { Catechin,epicatechin,quercetin,kaempferol,luteolin, } \\
\text { genistein, apigenin, myricetin, silymarin }\end{array}$ \\
\hline $\begin{array}{l}\text { Human colon } \\
\text { cancer }\end{array}$ & $\begin{array}{l}\text { Caco-2,HT-29,IEC- } \\
\text { 6,HCT-15 }\end{array}$ & Flavones,quercetin,genistein,anthocyanin \\
\hline $\begin{array}{l}\text { Human } \\
\text { leukemia } \\
\text { cancer }\end{array}$ & $\begin{array}{l}\text { HL-60,K562,4A5,B16 } \\
\text { mousemelanoma }\end{array}$ & Jurkat apigenin, quercetin, myricetin, chalcones \\
\hline
\end{tabular}

(Adapted from Vander et al., 2003)

Table.5 Effect of phenolic acid on various cell lines

\begin{tabular}{|c|c|c|}
\hline Cell/ Animal model & Phenolic acids and derivatives & Anticarcinogenic activities \\
\hline Caco-2 & $\begin{array}{l}\text { Ferulic acid, } \\
p \text {-coumaric acid }\end{array}$ & $\begin{array}{l}\downarrow \text { cell viability } \downarrow \text { G1 phase, } \uparrow S \text { and } \\
\text { G2 phase }\end{array}$ \\
\hline Caco-2 & $\begin{array}{l}\text { 3- } O \text {-Methylgallic acid, } \\
\text { gallic acid }\end{array}$ & $\begin{array}{l}\downarrow \text { cell viability, induce apoptotic } \\
\text { cell death, (-) G0/G1 phase; } \downarrow \text { S- } \\
\text { phase, (-)AP-1 (activator protein-1) }\end{array}$ \\
\hline HT-29 & $\begin{array}{l}\text { Caffeic acid, } \\
\text { coumaric acid, } \\
\text { ferulic acid }\end{array}$ & $\begin{array}{l}\text { (-) cell proliferation, }(-) \text { superoxide } \\
\text { anion production, }(-) \text { cell adhesion }\end{array}$ \\
\hline HCT15 & Caffeic acid & $\begin{array}{l}(-) \quad \text { cell growth, }(-) \text { colony } \\
\text { formation, } \downarrow \text { forward scatter, } \uparrow \\
\text { side scatter, } \uparrow \text { sub-G1 phase, } \uparrow \\
\text { ROS, } \uparrow \text { apoptosis }\end{array}$ \\
\hline HCT116 & 3,4-Dihydroxyphenylacetic acid & $\downarrow$ proliferative activity \\
\hline SW480, SW620 & Cycloartenyl ferulate & (-) cell growth, $\uparrow$ apoptosis \\
\hline$\overline{\text { DLD-1 }}$ & $\begin{array}{l}\text { Dicaffeoylquinic acid from sweet } \\
\text { potato leaf }\end{array}$ & (-) cell growth \\
\hline
\end{tabular}

(Adapted from Rosa et al., 2016) 
Table.6 Mechanisms by which bioactive compounds prevent cancer

\begin{tabular}{|c|c|c|}
\hline S.no. & Mechanism & Effect \\
\hline 1. & Antioxidant activity & $\begin{array}{l}\text { 1. Scavenge free radicals and reduce } \\
\text { oxidative stress } \\
\text { 2. Inhibit nitrosation and nitration } \\
\text { 3. Prevent DNA binding and damage }\end{array}$ \\
\hline 2. & DNA damage repair & \\
\hline 3. & Inhibition of cell proliferation & \\
\hline 4. & Induction of cell differentiation & \\
\hline 5. & Inhibition of oncogene expression & \\
\hline 6. & Induction of tumor suppress gene expression & \\
\hline 7. & Induction of cell cycle $\mathrm{G} 1$ arrest & \\
\hline 8. & Induction of apoptosis & \\
\hline 9. & Regulation of signal transduction pathway & \\
\hline 10. & $\begin{array}{l}\text { Enzyme induction and enhancing } \\
\text { detoxification }\end{array}$ & $\begin{array}{l}\text { 1. Phase II enzyme } \\
\text { 2. Glutathione peroxidase (GPX) } \\
\text { 3. Catalase } \\
\text { 4. Superoxidase dismutase (SOD) }\end{array}$ \\
\hline 11. & Enzyme inhibition & $\begin{array}{l}\text { 1. Cyclooxygenase-2 (COX-2) and } \\
\mathrm{PGE}_{2} \text { synthesis } \\
\text { 2. Inducible nitric oxide synthase } \\
\text { (iNOS) } \\
\text { 3. Xanthine oxidase } \\
\text { 4. Phase I enzyme (block activation of } \\
\text { carcinogens) }\end{array}$ \\
\hline $\begin{array}{l}13 . \\
14 . \\
15 .\end{array}$ & $\begin{array}{l}\text { Enhancement of immune functions and } \\
\text { invasion } \\
\text { Regulation of steroid hormone metabolism. } \\
\text { Regulation of estrogen metabolism } \\
\text { Antibacterial and antiviral effects }\end{array}$ & \\
\hline
\end{tabular}

Binding of electrophils

Induction of protective enzymes phase 2 with conjugating activities (GT or GST)

Apoptosis rate increases

Cell proliferation inhibition

Lipid peroxidation inhibition
H-donation (e.g. GSH-peroxidases) (Chahar et al., 2011)

In vivo and in vitro studies

In vivo and in vitro studies of flavonoid as anticancerous agent isolated from various herbs, vegetables, plants and fruits revealed that the inhibitory concentration IC50 of 24.948, 31.569 and 6.923 microgram $/ \mathrm{ml}$, 
respectively, on three cancer cell lines $\mathrm{MCF}$ 7, Hep G-2 and ES-2 showed dose-dependent inhibitory effect on hepatocellular carcinoma in laboratory mice (Li and Feng, 2013; Liu et al., 2011) (Figure 14).

Various normal cell lines follow the scheme of Figure 14 while progressing towards the cancer development or tumor formation. At first the radical generation is got enhanced and phase 1 metabolizing enzymes (CyP450) get activated which lead to the inactivation of phase 2 metabolizing enzymes (UDPglucuronyl transferase, quinine reductase and glutathione S-transferase). The cell lines were used are three leukemic cell lines (CEM, K562 and Nalm6), two breast cancer cell lines (T47D and EAC) and two normal cell lines (293T and MEF1). The cell lines were tested against the increasing concentration of quercetin and ellagic acid (Table 4). The cytotoxic effects were examined by either MTT or trypan blue in some cases. The cytotoxicity in lukemic cell line is observed in dose dependent manner, even at low concentration the cytotoxic effects were noticeable hence it is concluded that quercetin is significantly higher toxic in all cancer cell lines tan ellagic acid (Srivastava et al., 2016).

Flavonoids have been known as the enzyme inhibitors in vitro as well as ligands of receptors involved in singal transduction (Balasuriya and Rupasinghe, 2011). The phenolic nucleus is a structural unit that is favourable to molecular (non-covalent) interaction of flavonoids with proteins. The growth of U14 cervical cancer could be inhibited by Scutellaria baicalensis total flavonoids (STF), the cell proliferation inhibited by arresting cell cycle and cell apoptosis induced by regulating the expression of $\mathrm{Bax}$ and $\mathrm{Bcl}-2$ gene by treatment of STF (Peng et al., 2011). A recent study showed that fermented soy milk containing larger amount of genistein and daidzein than unfermented soy milk and isoflavone mixtures given to rats starting at 7 weeks of age, inhibited mammary tumorigenesis induced by 2-amino-1-methyl6-phenylimidazo [4,5-b] pyridine (PhIP) (Amin et al., 2009).

\section{Human clinical trials}

The increasing focus on flavonoids and their anticancer activities lead to its human trials, the trials are divided into two phases: phase 1 and phase 2. A phase 1 trial of quercetin is in dose increasing manner, a naturally occurring flavonoid with many biological activities including inhibition of a number of tyrosine kinases. Intravenous quercetin was found to inhibit lymphocyte tyrosine kinase 9 of 11 patients.

A case was studied in 1988 the patient was suffering from $4^{\text {th }}$ stage of ovarian cancer, who had not responded to six courses of cyclophosphamide or cisplatin chemotherapy but had fall in the CA125 tumor marker from 295 to 55 units/ml of intravenous quercetin $\left(420 \mathrm{mg} / \mathrm{m}^{2}\right) 3$ weeks apart. The phase 2 trial had been done with a dose of $1400 \mathrm{mg} / \mathrm{m}^{2}$ given in three weeks or weekly intervals. The maximum tolerated dose (MTD) is 1700 $\mathrm{mg} / \mathrm{m}^{2}$ three weekly but the vehicle dimethyl sulphoxide (DMSO) is unsuitable for further clinical development of quercetin (Lachumy et al., 2010). Flavopiridol is a novel semisynthetic flavone analogue of rohitukine, a leading anticancer compound from an Indian tree. Flavopiridol inhibits most cyclindependent kinases (CDKs) and displays unique anticancer properties. It is the first CDKs inhibitor to be tested in human clinical trials by National Cancer Institute (NCI) for the potential treatment of cancer and proliferative disorders (Huch et al., 2011). The various trials and evidences strongly favours the anticancer activities of flavonoids in various cell line cancers (Fukuyama et al., 2005). 
Phenolic acid and their role in combating cancer

More than 1 million new cases of colorectal cancer (CRC) are diagnosed worldwide each year. CRC is the third most common malignancy and fourth most common cause of cancer mortality (Table 5). The various research outcomes proved that genetic predisposition, diet, and lifestyle are some of the major contributing factors for colorectal cancer development (Terzia et al., 2010).

3,4-dihydroxyphenyl acetic acid (3,4DHPAA) is only phenolic acid that exhibited a considerable antiproliferative effect in $\mathrm{LNCaP}$ prostate cancer and HCT116 colon cancer cells (Gao et al., 2005). The effect of three phenolic acids (caffeic, coumaric and ferulic) were examined on superoxide anion production, adhesion and migration of colon adenocarcinoma (HT29-D4) cancer cell lines. Proliferation of tumor cells is effectively inhibited by caffeic, coumaric and ferulic acids also significantly inhibited superoxide production in HT29-D4 cells. The highest tested concentration $(200 \mathrm{mM})$ of caffeic acid in HT29-D4 cell line in which the superoxide anion concentration decreases by $77 \%$. HT29D4 cell adhesion was reduced by $79.8 \%$ at the higher tested concentration ferulic acid (200 $\mathrm{mM}$ ) (Figure 15 and 16) (Nasr et al., 2015).

The above evidences proves phenolic acids could inhibit colon cancer cell proliferation and induce cancer cell apoptosis in part through oxidant-mediated mechanisms (Figure 15 and 16). Therefore the intake of phenolic acid in food helps to cure cancer.

\section{Tannins preventing cancer}

Maplexins A-I are a series of structurally related gallotannins recently isolated from the red maple (Acer rubrum) species (Figure 17), during studies and analysis of properties of gallotannins reveals that it posses anticancer effect against human tumorigenic (colon, HCT-116; breast, MCF-7) and nontumorigenic (colon, CCD-18Co) cancer cell lines. Consequently, maplexin has anticancer property (Gonzalez-Sarria et al., 2012).

Ellitannin isolated from the $C$. ladanifer (Cistaceae) plant extract show inhibition properties, it inhibits the proliferation of M220 pancreatic cancer cells and MCF7/HER2 and JIMT-1 breast cancer cells (Barrajon-Catalan et al., 2010).

Isolated from Geranium wilfordii maxim (Geraniaceae) of hydrolysable tannin exhibit moderate cytotoxicity against cultured human tumor cell lines including A549, SK-OV-3, HT-1080, K562 and S180 in vitro (Li et al., 2013). Corilagin is a member of the tannin family that has been discovered in many medicinal plants and has been used as an antiinflammatory agent. It has anticancer properties against ovarian cancer cell lines and inhibit their growth, the cell lines are SKOv3ip, Hey and HO-8910PM Corilagin induced cell cycle arrest at the G2/M stage and enhanced apoptosis in ovarian cancer cells. Consequently, corilagin isolated from Phyllanthus niruri L. is a therapeutic agent against the growth of ovarian cancer cells via targeted action against the TGF$\beta /$ AKT/ERK/Smad signaling pathways (Jia et al., 2013).

\section{Mechanisms of control of cancer cell bioactive molecules}

Formation of reactive oxygen species (ROS) is a major step in the cancer progression in human cells. NADPH oxidase I (NOX 1), an enzyme that produce superoxide is overexpressed in colon and prostate cancer cell lines (Fukuyama et al., 2005) while its down regulation reverses tumor growth (Arnold et al., 2007) (Figure 18). 
ROS act as secondary messenger in several pathways that lead to increase in cell proliferation, resistance to apoptosis and activation of proto-oncogenes such as cFOS, cJUN and cMyc. In human hepatoma cells, ROS modulate the expression of $\mathrm{cFOS}$ and cJUN through PKB pathway. Lipoxygenases (LOX), cycloxygenases (COXs) and Xanthine oxidase (XO) are metalloenzymes whose catalytic cycle involves ROS such as lipid peroxyl radicals, superoxide, and hydrogen peroxide. LOXs and COXs catalyze important step in the biosynthesis of leucotrienes and prostaglandins from arachidonic acid, which is an important cascade in the development of inflammatory responses.

Flavonoids inhibits Ornithine decarboxylase (rate-limiting enzyme in polyamine biosynthesis) induced by tumor promoters, and inhibiting proliferation. The possible combination of distinct inhibition mechanisms: formation of non-covalent enzyme-inhibitor complexes, direct scavenging by flavonoid anti-oxidants of ROS inside or outside the catalytic pocket (with simultaneous oxidation of the flavonoids), chelation of the enzyme metal centers by the flavonoids, and enzyme inactivation by reactive aryloxyl radicals, quinones, or quinonoid compounds produced upon flavonoid oxidation that may eventually form covalent adducts with the enzyme (Sandhar et al., 2011).

The bioactive compounds from various food components are considered to be very effective in various immune stimulating, antimicrobial, anti-inflammatory and anticancer activities. There are various chemotherapies are also known but these therapies are very costly and are not affordable by common people. Therefore, in search of any alternative for chemotherapies various food components are processed and studied in resent past. These studies lighten up the importance of phenolic compounds such as flavonoids, phenolic acids, and tannins. The report shows various mechanisms by which these bioactive compounds help in curing cancer. The future prospective of phenolic compounds is considered very vast. The efficiency in vivo depends upon the supplementation of phenolic content in diet (Laura et al., 2016). Various processes are still under progress to find the amount of phenolic compounds in different species and their action on various cancer and tumor cells, it is proved that these compounds have potential to inhibit cancer cell proliferation and induce cancer cell apoptosis, and many more. However, additional studies are required to find out the specific mechanism and signal transduction responsible for regulation of cell cycle and apoptosis. The investigations show that the secondary metabolites have anti-cancer activities which are leading to the development of new clinical drugs from medicinal plants.

New technologies like nano particles for nano-medicines when applied along with plant derived bioactive compounds or drugs enhances anticancer activity.

The demands to cure cancer is extremely high, the chemically derived drugs have been developed and other cancer treatments preexist but these treatments have limitations due to their toxic effect on normal cells, also these drugs are very expensive which is not affordable by common patient.

Moreover the bioactive compounds extracted from various food sources from plant have been trialed on human under clinical conditions reveals that these compounds have no toxic effect on healthy human cells but increase in population lead to the exploitation of medicinal flora so to complete high demands of plant derived drugs need to be sustain, and mass cultivation is required. 


\section{References}

Alvesalo, J., H. Vuorela, P. Tammeia, M. leinonen, P. Saikku and Vuorela, P. 2006. Inhibitory effects of dietary compounds on Chlamydia pneumonia in cell cultures. Biochemical Pharmacology. 71(6):735-741.

Amin, A.R., O. Kucuk, F.R. Khuri and Shin D.M. 2009. Perspectives for cancer prevention with dietary compounds. Journal of Clinical Oncology.27(16): 2712-2725.

Ananga, A., V. Georgiev and Tsolova, V. 2013. Manipulation and engineering of metabolic and biosynthesis pathway of plant polyphenols. Current Pharmaceutical Design. 19(34): 61866206.

Arnold, R.S., J. He, A. Remo, D. Ritsick, Q. Yin-Goen, J.D. Lambeth, M.W. Datta, A.N. Young and Petros J.A. 2007. Nox1 expression determines cellular reactive oxygen and modulates c-fos induced growth factor interleukin-8 and Cav-1. American Journal of Pathology. 171(6): 2021-2032.

Balasuriya B.W.N. and Rupasinghe.2011. HPV Plant flavonoids as angiotensin converting enzymes inhibitors in regulation of hypertension. Functional Foods in Health and Disease. 1:172188.

Barrajon, C. E., S. Fernandez-Arroyo, D. Saura, E. Guillen, A. FernandezGutierrez, A. Segura-Carretero and Micol V. 2010. Cistaceae aqueous extracts containing ellagitannins show antioxidant and antimicrobial capacity and cytotoxic activity against human cancer cells. Food and Chemical Toxicology. 48: 2273-2282.

Brodowska K. M. 2017. Natural flavonoids: classification, potential role, and application of flavonoid analogues. European Journal of Biological
Research. 7(2): 108-123.

Chahar, M.K., N. Sharma, M.P. Dobhal and Joshi Y.C. 2011Flavonoids: A versatile source of anticancer drugs. Phcog Rev. 5(9): $1-12$

Dai J. and Mumper, M.J. 2010. Plant Phenolics: Extraction, analysis and antioxidant and their anticancer properties. Molecules.15: 7313-7352.

Davide B., G. Gattuso, E. Bellocco, A. Calderaro, D. Trombetta, A. Smeriglio, G. Lagana, M. Dagilia, S. Meneghini and Nabavi, S.M. 2017. Flavonones: citrus phytochemical with healthpromoting properties. BioFactors. 43(4): 495-506.

De la rosa, L.A., E. Alvarez-Parrilla and Gonzàlez-Aguilar G.A. 2010. Fruit and vegetable phytochemicals: chemistry, nutritional value, and stability. In: Laura A. de la Rosa (Ed.), 1st ed. Wiley J. \& Sons, Inc. Publication., pp. 134-170.

Esselen M., and Stephan, B. 2014. Foodborne topoisomerase inhibitors: Risk or benefit. Advances in Molecular Toxicology. 8: 123-171.

Fukuyama, M., K. Rokutan, T. Sano, H. Miyake, M. Shimada and Tashiro, S. 2005. Overexpression of a novel superoxide producing enzyme, NADPH oxidase 1 , in adenoma and well differentiated adenocarcinoma of the human colon. Cancer Letters. 221(1): 97-104.

Gao, K., A. Xu, C. Krul, K. Venema and Liu, Y.2005. Of the major phenolic acids formed during human microbial fermentation of tea, citrus, and soy flavonoid supplements, only 3,4Dihydroxyphenylacetic Acid has antiproliferative activity. Journal of Nutrition. 6: 52-57, 2005

Ghasemzadeh A., A. Nasiri, H.Z. Jaafar, A. Baghdadi, and Ahmad, I. 2014. Changes in phytochemical synthesis; chalcone synthesis, activity and 
pharmaceutical qualities of Sabah Snake grass (Clinacanthus nutrans L.) in relation to plant age. Molecules. 19(11): 17632-17648.

Ghasemzadeh A., Z.E.J. Hawa, R. Asmah and Ashkani, S. 2015. Secondary metabolites constituents and antioxidant, anticancer and antibacterial activities of Etlingera elatior (Jack) grown in different locations of Malaysia. BMC Complementary and Alternative Medicine.15: 335-340.

Ghasemzadeh, A., and Hawa Z. E. J.2013. Profiling of phenolic compounds and their antioxidant and anticancer activities in pandan (Pandanus amaryllifolius Roxb.) extracts from different locations of Malaysia. BMC Complementary and Alternative Medicine. 13: 341-345.

Goleniowski, M., B. Mercedes, R. M. Cusido, and Javier, P. 2013. Phenolic acid. In Ramawat, G., Merillon, J.M. (Eds.), Natural products, Springer-Verlag Berlin Heidelberg, pp. 1951- 1968. (doi: 10.1007/978-3-642-22144-6_64).

Gonzalez S., A., T. Yuan, and N.P. Seeram. 2012. Cytotoxicity and structure activity relationship studies of maplexins A-I, gallotannins from red maple (Acer rubrum). Food Chemistry and Toxicology. 50: 1369-1376.

Gupta E., S. Kaushik, S. Purwar, R. Sharma, A. K. Balapure, and Sundaram, S. 2017. Anticancer potential of steviol in MCF7 human breast cancer cells. Pharmacognosy Magazine. 13(51): 345350.

Han X., T. Shen, and Lou, H. 2007. Dietary polyphenols and their biological significance. International Journal of Molecular Sciences. 8(9): 950-988.

Hayouni, E.A., M. Abedrabba, M. Bouix, and Hamdi, M. 2007. The effects of solvents and extraction methods on phenolic contents and biological activities in vitro of Tunisian Quercus coccifera L. and Juniperus phoenicea L. fruit extract. Food chemistry. 105(3), 11261134.

Huang W.Y., Y. Cai, and Zhang, Y. 2010. Natural phenolic compounds from medicinal herbs and dietary plants used for cancer prevention. Nutrition and Cancer. 62(1): 1-20.

Huang, M.T., and Thomas, F. 1992. Phenolic compounds in food and cancer prevention. ACS Symposium Series, 507. Chapter 2, pp 8-34.

Huch, Z. C., A. Rahmat, A. Abdah, M. Akim, Banu, N., A.N. Mohd, and Othman, F. 2011. Anti-proliferative effects of pandan leaves (Pandaus amarylfolius), katan flower (Etlingera elatior) and turmeric leaves (Curcuma longa).Nutrition and Food science. 41(4), 238-241.

Jakubowicz G J., R.P. Paduch, T. Piersiak, K. Glowniak, A. Gawron, KandeferSzerszen, M. 2005. The effect of quercetin on pro-apoptotic activity of cisplatin in HeLa cells. Biochemical Pharmacology. 69(9):1343-1350.

Jayaprakasha, G., and Patil, B.S. 2007. In vitro evaluation of the antioxidant activities in fruit extracts from citron and blood orange. Food Chemistry. 101(1): 410-418.

Jia, L., H. Jin, J. Zhou, L. Chen, Y. Lu, Y. Ming and Yu, Y. 2013. A potential antitumor herbal medicine, Corilagin, inhibits ovarian cancer cell growth through blocking the TGF- $\beta$ signaling pathways. BMC Complementary Alternative Medicine. 13(10): 1472 1482.

Kar and Ashutosh. Pharmaocognosy and Pharmacobiotechnology ( $2^{\text {nd }}$ edition). New Age International Limited publishers, New Delhi, 332-600, 2007

Khoddami, M., A. Wilkes and Thomas, H.R. 2013. Techniques for analysis of 
phenolic compounds. Molecules. 18 (2), 2328-2375.

Lachumy, S.J.T., S. Sasidharan, V. Sumathy, and Zuraini, Z. 2010. Pharmacological activity, phytochemical analysis and toxicity of methanol extract of Etlingera elatior (torch ginger) flower. Asian Pacific Journal of Tropical Medicine. 3(10), 769-774.

Li, J., and Feng-Ting, L. 2013. Why bortezomib cannot go with 'green'? Cancer Biology and Medicine.10: 206213.

Li, P., L. Zhao, Y. Du, Y. Feng and Li, Y. 2013. Hydrolysable tannins and related compound having cytotoxic activity of Geranium wilfordii maxim. Advances in Journal of Food Science and Technology. 5: 255-257.

Liu, P.X., J. Gao, Y.J. Chen, W. Long, X. Shen and Tang W.S. 2011. Anticancer activity of total flavonoids isolated from Xianhe Yanling Recipe. Chinese Journal of Integrative Medicine. 17(6): 459-463.

Manson, M. 2003. Cancer prevention - the potential for diet to modulate molecular signaling, science Direct Trends in molecular medicine. 9(1):11-18.

Nasr, B. N., J.S. Kilani, H. Kovacic, L. Chekir-Ghedira, and Ghedira, K. 2015. The effects of caffeic, coumaric and ferulic acids on proliferation, superoxide production, adhesion and migration of human tumor cells in vitro. European Journal of Pharmacology. 766; 99-105.

Nicola, T. 2014. Flavonoids: Definition, structure and classification. www.tuscanydiet.net/2014/01/22/flavon oids-defintion-structure-classification.

Nile, S.H., and Park, S.W. 2014. HPTLC analysis, antioxidant and antigout activity of Indian plants. Frontiers in life sciences. Iranian Journal of Pharmaceutical Research. 12, 531-539.
Okuda, T., and Ito, H. 2011. Tannins of constant structure in medicinal and food plants-hydrolyzable tannins and polyphenols related to tannins. Molecules. 16, 2191-2217.

Pandey, K.B., and Rizvi, S.I. 2009. Plant polyphenols as dietary antioxidants in human health and disease. Oxidative Medicine and Cellular Longevity. 2(5): 270-278.

Paur, I., M.H. Carlsen, B.L. Halvorsen, and Blomhoff, R. 2011. Antioxidents in herds and species: Role in oxidative stress and redox signaling. In: Benzie I.F.F., and Wachtel-Galor S, (Eds). Source herbal medicine: Bimolecular and clinical Aspects. $2^{\text {nd }}$ edition. Boca Raton (FL): CRC press.

Peng Y., Q.W. Li, and Jian, L. 2011. Antitumor activity of Scutellaria baicalensis Georgi total flavonoids on mice bearing U14 cervical carcinoma. African Journal of Biotechnology. 10(82), 19167-19175.

Porcza, L.M., S. Claire, and Mridula, C. 2016. Honey and cancer: current status and future directions. Diseases. 4: 30-36.

Ren, W., Q. Zhenhua, W. Hongwei, Z. Lei and Li, Z. 2003. Flavonoids promising anticancer agents. Medicinal Research Reviews. 4: 519-534,

Rosa, L.S., N.J.A. Silva, N.C.P. Soares, M.C. Monteiro and Teodoro, A.J. 2016. Anticancer properties of phenolic acid in colon cancer, Journal of Nutrition and Food Science. 6(2): 468-478.

Rossi, M., C. Bosetti, E. Negri, P. Lagiou and La Vecchia, C. 2010. Flavonoids, proanthocyanidins, and cancer risk; a network of case-control studies from Italy. Nutrition and Cancer. 62(7): 871877.

Rossi, M., W. Garavello, R. Talamini, E. Negri, C. Bosetti, L. Dal, P. Lagiou, A. Tavani, J. Polesel, L. Barzan, V. Ramazzotti, S. Franceschi and Vecchia, 
C. 2007. Flavonoids and the risk of oral and pharyngeal cancer; a case control study from Italy. Cancer Epidemiological Biomarkers Preview. 16(8), 1621-1625.

Sandhar, H.K., B. Kumar, S. Prasher, P. Tiwari, M. Salhan and Sharma, P. 2011. A review of phytochemistry and pharmacology of flavonoids. International Pharmaceutical Sciences. $1: 25-41$.

Senawong, T., K. Somprasong, M. Suwatchai, K. Jeeranan, S. Gulsiri, W. Paweena and Sirinda. 2014. Phenolic acid composition and anticancer activity against human cancer cell lines of the commercially available fermentation products of Houttuynia cordata. Science Asia. 40:420-427.

Srivastava, S., R. Ranganatha, S.M. Hedge, M. Nishana, S.K. Tadi and Srivastava, M. 2016. Quercetin, a natural flavonoid interacts with DNA, Arrests cell cycle and causes tumor regression by activating mitochondrial pathway of apoptosis. Scientific Reports. 6:240-49, 2016

Terzia, J., S. Grivennikov, E. Karin and Karin, M. 2010. Inflammation and colon cancer. Gastroenterology. 138, 2101-2114.

Tsao, R. 2010. Chemistry and Biochemistry of dietary polyphenols. Nutrients. 2(12): 1231-1246.

Vander, L.E., H.M. Roelofs, F.M. Nagengast and Peters W, H. 2003. Induction of rat hepatic and intestinal UDPglucuronosyl transferases by naturally occurring dietary anticarcinogens. Carcinogenesis. 24:1651-1656.

Veronique, C. 2015. Phenolic compounds from plants to food. Journal of Agriculture and Food Chemistry. 11: 153-177.

Vuong, Q.V., S. Hirun,, T.L.K. Chuen, C.D. Goldsmith, S. Murchie, C.B. Michael, A.P Phoebe and Christopher J. S. 2014.. Antioxidant and anticancer capacity of saponin-enriched Carica papaya leaf extracts. International Journal of Food Science and Technology. 50: 169-177,

Wei, J., X. Huo, Z. Yu, X. Tian, S. Deng, C. Sun, L. Feng, C. Wang, X. Ma and Jia, J. 2017. Phenolic acids from Balanophora involucrata and their bioactivities. Fitoterapia. 121: 129-135.

Widsten, P, C.D. Cruz, F.C. Fletcher, M.A. Pajak and McGhie, T.K. 2014. Tannins and extracts of fruit byproducts: Antibacterial activity against food borne bacteria and antioxidant capacity. Journal of Agricultural and Food Chemistry. 62: 11146-11156.

\section{How to cite this article:}

Mukesh Chander. 2018. Anticancer Efficacy of Some Plant Phenolics - A Recent Scenario. Int.J.Curr.Microbiol.App.Sci. 7(10): 1746-1768. doi: https://doi.org/10.20546/ijcmas.2018.710.200 